\title{
ESTRATEGIAS PARA ABORDAR LA INFORMACIÓN AUDIOVISUAL SOBRE EL PATRIMONIO INMATERIAL DE LOS TERRITORIOS DESDE UNA PERSPECTIVA INTERACTIVA: EL PAPEL DE LAS REDES SOCIALES.
}

Esteban Galán-Cubillo 1: Universitat Jaume I de Castellón. España

esteban.galan@com.uji.es

\section{RESUMEN}

La implantación de la televisión digital terrestre en España, lejos de suponer un enriquecimiento en la variedad y calidad de los contenidos televisivos ha supuesto bien al contrario un empobrecimiento de la oferta. Las cadenas de televisión han adoptado estrategias de producción low-cost como respuesta a la merma de los ingresos publicitarios. El dinero que las televisiones ingresan por publicidad se ha visto drásticamente limitado debido a la atomización de las audiencias en un escenario de exceso de oferta. Esto ha obligado a las televisiones a desarrollar estrategias para diferenciar su oferta del resto de las cadenas. Una de las vías para conseguirlo es la especialización de los contenidos. El actual escenario de revitalización del patrimonio cultural y explotación del potencial turístico vinculado a las fiestas tradicionales que se ha experimentado desde finales del siglo XX hasta la actualidad, ofrece a las televisiones un material de enorme valor para conseguir esa especialización en los mensajes televisivos. Estos contenidos relacionados con la historia y la cultura son una oportunidad para contar historias que aportan al espectador novedad, frescura, proximidad y participación. La participación e integración de una comunidad que se produce en cualquier evento tradicional, se une a la oportunidad que ofrecen las redes sociales, para que los protagonistas de la fiesta dispongan de la oportunidad de poder participar en la elaboración de la escaleta proponiendo temas, ideas y sugerencias que hacen que la confección del programa sea interactiva y abierta a la audiencia. El caso del programa Cor de Festa en Televisión Valenciana con más de 400 emisiones y casi seis años en antena es un buen ejemplo de ello.

PALABRAS CLAVE: Televisión - Evento tradicional - Patrimonio inmaterial - Redes sociales - Información audiovisual

\footnotetext{
${ }^{1}$ Autor correspondiente

Esteban Galán-Cubillo: Profesor de la Universitat Jaume I de Castellón, España.
} 


\title{
STRATEGIES TO RAISE THE AUDIOVISUAL INFORMATION ABOUT THE IMMATERIAL HERITAGE OF THE TERRITORIES FROM AN INTERACTIVE PERSPECTIVE: THE ROLE OF THE SOCIAL NETWORKS
}

\begin{abstract}
The introduction of digital terrestrial television in Spain, far from being an enrichment of the variety and quality of television content, on the contrary has brought an impoverishment of the offer. The television networks have adopted strategies of low-cost production in response to declining advertising revenue. The television advertising revenue has been severely limited due to the fragmentation of audiences in a scenario of excess of offer. This has forced broadcasters to develop strategies to differentiate their offerings from competitors. One way to achieve this is the specialization of the content. The current stage of revival of cultural heritage and tourism potential exploitation linked to traditional festivals which have been experienced since the late twentieth century to the present, offers broadcasters a material of great value to get that specialized in television messages. These contents related to the history and culture are an opportunity to tell stories that bring the viewer newness, freshness, proximity and participation. Participation and integration of a community that occurs in any traditional event, binds to the opportunity offered by social networks, so that the protagonists of the party have the chance to participate in the development of the proposed issues, ideas and suggestions that make designing the program interactive and open to the audience. The program Cor de Festa in Television Valenciana with over 400 broadcasts and almost six years on the air is a good example of above explained.
\end{abstract}

KEY WORDS: Television - Traditional event - Immaterial Heritage - Social networks - Audiovisual information

\section{INTRODUCCIÓN}

En el presente trabajo se analiza el programa Cor de Festa de la televisión autonómica Canal 9, en la región de la Comunidad Valenciana en España. La variedad y los orígenes de los eventos tradicionales que articulan el panorama festivo de un territorio poseen tanta riqueza, que resulta imposible compartimentar el evento tradicional dentro de una única categoría. Sin embargo, pese a la gran diversidad existente, encontramos un ítem que engloba a todos los productos televisivos que abordan manifestaciones tradicionales de un territorio. La característica que diferencia a estos espacios televisivos es que dan a conocer cuestiones culturales. En este sentido, y atendiendo al poder que tiene la televisión para moldear el universo simbólico y transmitir la tradición cultural al televidente, es donde se centra el objeto de la investigación. La transmisión a través de un mensaje audiovisual de un evento 
vinculado a la tradición cultural de una comunidad le permite diferenciarse a través de una oferta turística de primer nivel que singulariza al territorio y da a conocer de forma implícita, la arquitectura, la gastronomía, el paisaje y la riqueza artística de la región y de sus gentes, que en definitiva son los protagonistas del evento tradicional. Por tanto, la hipótesis de este trabajo es que la transmisión del evento tradicional en televisión se erige como el agente dinamizador en un doble sentido: permite a las televisiones ofrecer contenidos especializados que fidelizan a su audiencia y facilita a su vez, la labor de diferenciación en aras de obtener la singularidad que buscan las localidades para posicionar su imagen de marca de ciudad de cara a poder acceder al mercado turístico en condiciones favorables. La cultura brinda al territorio una oportunidad de diferenciación decisiva para configurar en el imaginario colectivo una imagen de marca.

La televisión regional con un territorio de influencia más acotado que una televisión de ámbito nacional y con una infraestructura y unos medios técnicos y humanos superiores a los que cuenta una televisión de ámbito local, parece el medio más idóneo para la comunicación del evento tradicional en televisión. La televisión de ámbito autonómico o regional ofrece una audiencia potencial en un ámbito geográfico de proximidad al evento que permite que el espectador pueda participar en la fiesta que el programa presenta. El programa de Cor de festa $393^{2}$, objeto de análisis de este trabajo se emitió desde Requena el sábado 3 de septiembre a las $13 \mathrm{~h}$ permitiendo al público de Valencia, Alicante o Castellón poder acercarse a la localidad de Requena para disfrutar de los eventos que se celebran esa tarde-noche del 3 de septiembre y al día siguiente día 4 de septiembre.

Abordar una materia tan compleja y con tantas aristas como la de la presente investigación, exige una técnica de investigación que combine técnicas de análisis cualitativo con técnicas cuantitativas. La observación documental se ha visto combinada con un trabajo de campo consistente en la recogida y análisis de los diferentes programas que lleva realizando Cor de festa desde el año 2006. El triángulo metodológico se complementa con un trabajo de campo bajo la técnica de la observación participante que ha servido para contrastar, enriquecer y matizar los resultados obtenidos. En este sentido, es importante destacar que el autor viene colaborando con el programa Cor de festa desde 2008 desempeñando tareas de

\subsection{El evento tradicional como unidad comunicativa básica}

A la hora de comunicar el evento tradicional hay que tener en cuenta que la característica que define un programa en el que se aborda el evento tradicional es su diversidad. La variedad y los orígenes de los eventos tradicionales que articulan el panorama festivo de un territorio poseen tal riqueza, que resulta imposible compartimentar el evento tradicional dentro de una única categoría. Aunque la gran mayoría de eventos tienen raíces religiosas, otros muchos pueden conmemorar un

${ }^{2}$ http://www.rtvv.es/va/cordefesta/Cor-festa-Cap_13_547875211.html 
hecho significativo en la vida de una localidad: el nacimiento de algún personaje histórico, inundaciones, epidemias, guerras... Pese a la gran diversidad existente, encontramos un ítem que engloba a todos los productos televisivos que abordan manifestaciones tradicionales de una comunidad.

La característica que diferencia a estos espacios televisivos es que dan a conocer cuestiones culturales. Justamente, esta circunstancia es la que obliga a comunicar con entusiasmo y con claridad. La claridad es un requisito sine qua non, para explicar los conceptos nuevos para el espectador, Alejandro Salgado y Gloria Campos (2010). Sin embargo, el esfuerzo divulgativo es estéril si el acto comunicativo no va acompañado de entusiasmo. Además de explicar e introducir los ítems imprescindibles para acceder a la comprensión del evento, es necesario contagiar a la audiencia el interés por los asuntos que se tratan. Hay que huir de entusiasmos fingidos o de sobrevaloraciones artificiales del acto mostrado. La comunicación televisiva requiere naturalidad y autenticidad ante las cámaras. Por tanto, para que el presentador pueda actuar con naturalidad debe dominar, tener autoridad en la materia que aborda. En el programa Cor de Festa el presentador y los reporteros del programa, no solamente gozan de experiencia y habilidad como profesionales del medio audiovisual sino que son en muchos casos miembros y protagonistas de las propias fiestas y tradiciones que comunican participando en las entradas de Moros y Cristianos, las Comisiones falleras o en las fiestas de la Magdalena de Castellón o las Hogueras de Alicante. Cor de Festa, por tanto, no solamente registra y traslada las fiestas y tradiciones de la Comunidad sino que participa de ellas vertebrando y hermanando a todas las localidades.

\subsection{Tipología de eventos tradicionales}

Aunque habitualmente se ha podido utilizar el criterio religioso para clasificar las fiestas, esta categorización no resulta útil para el análisis. El origen religioso o pagano de una tradición no determina ni las características de la fiesta ni los roles de participación de los vecinos y visitantes en la fiesta. Esto es así porque muchas fiestas que hoy se consideran religiosas, tienen su origen en realidad en celebraciones profanas en las que se conmemoraba la llegada de la cosecha o el cambio de estación. También sucede a la inversa, es decir, fiestas que hoy consideramos paganas tuvieron su origen en celebraciones o tradiciones religiosas. Por tanto, descartando como herramienta de análisis el carácter o no religioso de la fiesta, resulta más útil analizar la propia fiesta en función de si posee un carácter más espectacular o necesita de la participación de los vecinos. El evento espectacular es aquel que busca, que necesita ser mirado. En esta categoría de fiesta encontramos, por ejemplo, Las Fallas de Valencia, las "mascletás" o los castillos de fuegos artificiales.

Sin embargo, la fiesta también puede tener un carácter más participativo, es decir, el protagonista de la fiesta no es un monumento o una representación sino es el propio festero, Antonio Ariño Villarroya (1998). En esta categoría de fiestas participativas encontramos ejemplos como La Tomatina de Buñol, La Zurra de Requena o La Cordà de Paterna, todos ellos presentes en el programa 393 de Cor de Festa analizado en el 
presente estudio. Sin embargo, esta clasificación aunque es útil para analizar eventos (que no obstante es el objeto del presente estudio explicitado en título del trabajo) no es demasiado útil para el estudio de unas fiestas en su conjunto. Los programas de fiestas que buscan contentar a todas las edades y a todos los perfiles de público (habitantes, turistas etc.) contienen actos más espectaculares y otros más participativos siendo imposible clasificar una fiesta en su conjunto como espectacular o como participativa en un sentido puro. A su vez, también podemos encontrar algunos eventos en los que se aúna el carácter espectacular y participativo en una misma fiesta. El ejemplo más singular son las Entradas de Moros y Cristianos. Parte de su reciente éxito reside en que el grado de participación en las fiestas es muy amplio y que mientras desfila el bando moro, el bando cristiano asiste al desfile y aplaude y cuando lo hace el bando cristiano es el bando moro quien presencia el espectáculo y anima y disfruta con la música y la variedad de espectáculos (del origen más variopinto) que se integran en el desfile.

Dentro de la categoría participativa existe una categoría específica que se ha venido en denominar ludomaquia promiscua. "Es un festejo consistente en una lucha inofensiva (...) en la que impera el combate cuerpo a cuerpo y la mezcla confusa (...) hallándose los contendientes envueltos y empapados en las humedades/olores/chispas del producto que se utiliza como arma" (Ariño, 1998, p.170). La ludomaquia promiscua por su duración acotada en el tiempo, su espectacularidad audiovisual y su carácter de participación masivo se adapta excepcionalmente a las características del mensaje televisivo. De esta manera en el programa 393 de Cor de Festa analizado encontramos un total de cuatro ludomaquias promiscuas, a saber:

a)

Zurra de Requena, donde se produce una batalla de vino que se suministra desde cisternas en los recipientes más insospechados y una guerra de agua que cae desde los balcones b) a través de mangueras y cubos lanzados por los propios vecinos.

b) Tomatina de Buñol. Es hoy probablemente la fiesta española más conocida a nivel internacional. Su origen se remonta a 1944 cuando un grupo de jóvenes de Buñol se lanzaron tomates con las fuerzas del orden, (Díaz, 2009). En los años 70 se dio a conocer a nivel nacional y empezó a atraer turistas extranjeros. Sin embargo, fue la aparición en la portada del diario Washington Times en 1997 lo que supuso su consolidación internacional.

c)

Batalla de Confeti de Morella que se produce después del pregón de anuncio de las fiestas del Sexenio.

d)

La Cordà de Paterna. Es una batalla de cohetes que hoy se realiza dentro de una jaula para mayor seguridad de los vecinos y espectadores. Las legislaciones europeas en el terreno de la pólvora han obligado a luchar para mantener la tradición y han hecho que el propio "coeter major" y símbolo de la fiesta, el venerable octogenario Pepín Damián haya viajado a Bruselas junto con autoridades 
locales para defender la necesidad de mantener esta tradición, pese al riesgo que conlleva siempre el manejo de pólvora.

\section{METODOLOGÍA}

\subsection{Selección y estudio de la muestra}

Fue el 9 de mayo de 2006 cuando este programa especializado en las fiestas iniciaba sus emisiones en Televisión Valenciana. Después de más de 400 emisiones Cor de festa se ha consolidado como el espacio televisivo de referencia sobre las numerosas fiestas que ofrece la Comunidad Valenciana. El espacio recorre pueblos y ciudades de las provincias de Valencia, Castellón y Alicante para cubrir los actos más brillantes y multitudinarios de las fiestas con más renombre, pero también las celebraciones tradicionales y festivas de las localidades más pequeñas.

Cor de festa en la actualidad es un programa semanal que emite Canal 9 los sábados a las 13 horas y que tiene una duración aproximada de una hora. Presentado y dirigido por Julio Tormo Ases, se van presentando reportajes vinculados con la actualidad festiva que profundizan en el evento narrado con un estilo directo y donde los implicados y los expertos explican y valoran el acto siguiendo una estructura lineal. En ocasiones, dado que el programa se emite el sábado por la mañana, víspera de muchas fiestas que se celebran en sábado y domingo, es necesario presentar los antecedentes y los preparativos de las fiestas en las que la audiencia puede participar horas más tarde.

Para este artículo se ha elegido el programa 393 de Cor de Festa. La elección del programa objeto de análisis se ha debido a que en el programa objeto de análisis, se abordan los eventos festivos de la última semana de agosto y la primera de septiembre que tradicionalmente es uno de los periodos donde se concentran un mayor número de fiestas en las localidades valencianas y españolas. El programa comienza con la imagen de Julio Tormo, presentador del programa, caminando por la Avenida de Arrabal de Requena delante de una charanga que anticipa un pasacalle festero. Las presentaciones a los contenidos del programa y las diversas entrevistas se graban desde Requena con motivo de la celebración de la fiesta de la Vendimia. La elección de Requena además de por la entidad de su fiesta (es la fiesta en honor al vino más antigua de España) se refuerza durante el programa porque en el momento de emisión del programa (Sábado a las 13:00h) las fiestas están en curso y quedan importantes actos para el sábado por la tarde y el domingo para los que el programa sirve como reclamo. Los reporteros del programa van comunicando los contenidos fundamentales referentes a las fiestas de la semana anterior y de la próxima semana.

Entre ellas destacan las Fiestas de la Vendimia de Requena, la Tomatina de Buñol, las Fiestas de Moros y Cristianos de Ontinyent o la Cordà de Paterna. Sin embargo, 
también hay sitio para mostrar fiestas menos conocidas como la Entrada Mora y Cristiana de Vilanova de Castelló o la Fiesta del Reparto de panes en el Genovés.

\section{ANÁLISIS Y DISCUSIÓN}

\subsection{Análisis de las estrategias audiovisuales empleadas}

Los reportajes de Cor de festa se ruedan sin guión, se filma lo acaecido durante el evento y se añade después en el montaje aquellas imágenes de archivo necesarias para complementar el reportaje. No existe ninguna estructura preconcebida que determine a priori la filmación, el reportero está en el evento, participa en muchas ocasiones de él y va registrando de forma secuencial lo que allí va ocurriendo.

Se trata de acompañar con el operador de cámara la celebración del acontecimiento, de estar al lado del evento, pero no como un observador externo, sino como un participante más de la fiesta. Todo se subordina a esa cercanía, a las personas presentes y a los afectos y las emociones que despierta el acto. Aunque el rito siempre requiere una serie de acciones previamente conocidas, no se sabe de antemano lo que puede ocurrir.

La reacción espontánea de la gente siempre es impredecible y el contacto del punto de vista de la cámara con el punto de vista del protagonista de la fiesta, en ocasiones proporciona momentos de gran intensidad dramática. El montaje posterior siempre respeta la cronología de rodaje, presentando una estructura acumulativa y azarosa del viaje, de conocimiento del proceso en el que fiesta y televisión confluyen. El rodaje, por tanto, es flexible y siempre queda abierto a cualquier reorientación de la idea inicial. El ratio más habitual de imágenes en bruto con respecto a las imágenes editadas es de 10:1. Por tanto, en este tipo de programa, las tomas no son una repetición de la anterior, sino que cada plano tiene una entidad autónoma, es un plano en sí mismo, único y singular.

El método de trabajo más habitual es aprovechar los minutos previos a la celebración del evento para grabar planos recurso de los asistentes y para entrevistar a los protagonistas del evento. Durante la celebración del evento, es habitual que se lleve a cabo un seguimiento riguroso del mismo, pero variando la escala de planos sin por ello detener la grabación. La posibilidad de grabar varios minutos de imágenes sin detener el registro, nos permite disponer de una continuidad sonora del evento que ofrece múltiples posibilidades en el montaje. Los fragmentos de la grabación que deben ser descartados por cuestiones técnicas (barridos, enfoques, cambio de escala de plano) pueden ser sustituidos por los planos recursos registrados previos al evento y de esta manera podemos aprovechar la continuidad sonora registrada en la grabación. La fase de montaje juega por tanto, un papel decisivo. Es en este momento donde se construye de forma efectiva la historia. 


\subsection{El empleo de los elementos del lenguaje sonoro: la ambientación musical}

El empleo de música folklórica propia del lugar geográfico, en un programa donde el protagonismo lo tiene el folklore y las fiestas populares, resulta conveniente. Sin embargo, también es conveniente contemplar la posibilidad de utilizar músicas cuya cadencia y colorido orquestal posea unas características tímbricas y melódicas similares a las de la región objeto del reportaje, (Beltrán, 2005). También es útil contemplar la utilización canciones e himnos tradicionales de la región en una versión actualizada o versionada desde un estilo musical diferente para el que originariamente se concibió.

El silencio es a menudo el gran olvidado dentro de la producción audiovisual. Sin embargo, en un programa donde el protagonismo lo tiene la música y el ambiente, los silencios no pueden interpretarse con la ausencia absoluta de sonido.

Tampoco los instantes de recogimiento pueden consistir en una sucesión inconexa de toses, de entrecortados murmullos o del inoportuno ruido del tráfico que rodea una recogida procesión. Para completar un trabajo de sonorización que potencie el discurso es importante disponer de fondos sonoros con los que falsear y disimular aquellas partes del acto que por su propia naturaleza no pueden ser asfaltadas con música y que requieren un fondo sonoro que envuelva y ubique la acción pero que no distraiga ni moleste al espectador. El silencio en ocasiones puede utilizarse con un interés narrativo.

Cor de Festa es un programa de transmisión de tradiciones, de folklore, en definitiva de cultura. Por tanto, la palabra como una manifestación eminentemente verbal transmisora de la tradición universal es la herramienta clave para divulgar y posibilitar la pervivencia del fenómeno objeto de la comunicación. En ocasiones la palabra deja de ser una herramienta y se convierte en protagonista, dado que el propio hecho de decir, nos transmite la riqueza oral de un territorio.

En la Comunidad Valenciana, ámbito geográfico de difusión del programa, existe un bilingüismo en el que conviven el castellano y el valenciano. La riqueza idiomática es amplísima, podemos encontrar diferentes acentos, una gran variedad de vocabulario y una forma de construir el discurso por parte de los protagonistas que varía en función de su procedencia geográfica.

En el mismo programa 393 coexisten en armonía el valenciano que se habla en Ontinyent o Morella, con el castellano parlante de Requena o el bilingüismo que podemos encontrar en las ciudades de Castellón o de Valencia. La palabra es también el elemento conductor del programa Cor de Festa a través de la cual su presentador, desde un lugar vinculado con la actualidad festiva, comunica su entusiasmo y emoción hacia los eventos abordados en los reportajes.

\subsection{El papel de las redes sociales}


Sin embargo, este trabajo de registro y comunicación de las tradiciones y fiestas de la Comunidad se realiza en equipo. Este equipo entendido de forma amplia está formado por todos aquelllos telespectadores que por vía telefónica, telemática o fundamentalmente a través del facebook del programa, hacen llegar sus comentarios, sugerencias y propuestas para llevar a cabo reportajes de los eventos que se desarrollan en su localidad.

El facebook de Cor de Festa tiene un funcionamiento absolutamente interactivo en el que el programa informa de los eventos que se van a cubrir y de aquellas noticias relacionadas con la fiesta y a su vez recibe la información y los comentarios de múltiples actos que se desarrollan por toda la Comunidad y que pueden ser susceptibles de ser cubiertos por los reporteros del programa. Facebook se ha constituido en el canal de retroalimentación necesario entre la dirección del programa y su público, de forma que se dispone de una información continua de los gustos e intereses de la audiencia. Esta información tiene un valor cualitativo superior que los fríos índices de la curva de audiencia. El equipo de Cor de Festa, además de estar integrado por todos los telespectadores del programa, también está representado por la plantilla de trabajadores del programa. Cor de Festa visibiliza su trabajo y acerca a los espectadores al equipo del programa a través de ráfagas que sirven como elemento separador, para aligerar la acción o para introducir notas de humor y desenfado dentro del discurso.

En estas ráfagas es habitual encontrar a los miembros del equipo de producción y realización del programa llevando a cabo tareas de arreglo de vestuario, traslado del material o simplemente degustando el plato que con anterioridad ha acompañado el presentador durante su preparación. De esta manera, tanto en la mostración del hacer televisivo, como en la interacción con el espectador a la hora de elaborar y decidir los contenidos de la escaleta del programa, Cor de Festa es un programa que se adapta perfectamente al escenario televisivo actual.

\section{CONCLUSIONES}

Uno de los primeros territorios en entender la importancia de asociar la promoción turística al evento tradicional fue la sociedad valenciana a principios del siglo $X X$ vinculando la promoción turística incipiente en aquellos años con la elección de las Fallas como fiesta que simbolizaba el espíritu y la esencia de un territorio que se quería dar a conocer. En la simplicidad del mensaje (Fallas y buen tiempo) reside el éxito de la promoción turística iniciada hace ahora más de cien años. Fiestas como las Fallas de Valencia, la Tomatina de Buñol o los Sanfermines de Pamplona nos han enseñado que para dar a conocer las fiestas y explotarlas como motor turístico de un territorio, dentro del programa festero hay que elegir un evento que se adapte al lenguaje audiovisual. La categoría de fiesta participativa denominada como ludomaquia promiscua consistente en una batalla festiva en la que los contendientes utilizan un producto tradicional como arma (agua, tomates, vino, cohetes etc.) parece ser la categoría de evento que por su plasticidad y riqueza de matices mejor se adapta 
al lenguaje audiovisual y mayor potencial tiene, por tanto, de difusión nacional e internacional.

Al estar trabajando con un material cultural que atañe a las raíces de una sociedad y a su identidad colectiva, la pauta fundamental para llevar a cabo un acercamiento audiovisual con éxito debe ser el respeto. El respeto a la cronología del evento, a suliturgia y a su sentido más fundamental. Para poder transmitir estos valores con la mayor fidelidad posible es útil dar la palabra a los protagonistas del evento que son quienes nos pueden trasladar no sólo la información más cercana, sino lo fundamental cuando hablamos de tradición: la emoción y los sentimientos que despierta la celebración del rito. El estilo visual debe subordinarse a las características del evento narrado haciendo un especial hincapié en la captación del sonido ambiente que singulariza y dota de vida al relato audiovisual y al uso de música tradicional vinculada con la fiesta y el territorio. La palabra junto con el sonido ambiente y la música es el vehículo esencial para la transmisión de la cultura y la tradición de la liturgia festiva. Sin embargo, esa palabra no es sólo vehículo o herramienta para la narración sino que también se ofrece como oportunidad para que a través de las redes sociales, los protagonistas de la fiesta dispongan de la oportunidad de poder participar en la elaboración de la escaleta proponiendo temas, ideas y sugerencias que hacen que la confección del programa sea interactiva y abierta a la audiencia.

La televisión si aspira a seguir siendo ese medio que configura el universo de lo pensable, necesita dotarse de la retroalimentación que proporcionan las redes sociales con una perspectiva global, sin desatender ninguno de los procesos, la transparencia en los procesos productivos debe ser un imperativo que determine el nivel cualitativo y ético del hacer televisivo. Los antes espectadores, ahora usuarios deben participar y sentirse partícipes de la configuración del espacio televisivo, en definitiva de su propio espacio.

\section{REFERENCIAS}

Ariño Villarroya, A. (1998). Fiesta y turismo en la Comunidad Valenciana. Revista Valenciana d'Estudis Autonòmics, (25).

Barroso, J. (1996). Realización de los géneros televisivos. Madrid: Síntesis..

Beltrán Moner, R. (2005). La ambientación musical en radio y televisión. Madrid: RTVE Instituto.

Bernad Monferrer, M${ }^{a}$ E. \& Mut Camacho, M. (2010) Importancia del Evento como instrumento de proyección del territorio. El evento tradicional como dinamizador y generador de riqueza. En Tenerife, II Congreso Internacional Latina de Comunicación Social. Recuperado el 10 de Agosto del 2011, de http://www.revistalatinacs.org/10SLCS/actas_2010/estela.pdf. 
Díaz Arias, R. (2009) Localización de la información internacional en un mundo global. Revista Latina de Comunicación Social, (64). Consultado el 10 de Agosto de 2011. de www.revistalatinacs.org/09/art/31_830_54_UCM/Rafel_Díaz_Arias.html.

Fernández, C. \& Galán, E. (2011) El formato low-cost en televisión (uso y abuso del "directo sucedáneo. En Sevilla. Universidad de Sevilla. I Congreso de Ética de la Comunicación de Sevilla.

Galán, E. (2008). Televisión en virtual. Madrid: IORTV.

Saborit, J. (2003). Guía para ver y analizar El sol del membrillo. Valencia: Nau Llibres.

Salgado, A. \& Campos, G. (2010). Palabra y televisión. Las cualidades formales de la presentación de formatos de entretenimiento. En Balsebre, A. El poder creativo de la palabra (pp. 547-569) Barcelona: Icono 14.

Torras, D. (2010). El silencio: el elemento olvidado en la expresión audiovisual. Sensación de silencio y percepción del silencio. En Balsebre, A. El poder creativo de la palabra (pp. 633-657) Barcelona: Icono 14.

\section{Esteban Galán-Cubillo}

Doctor en Comunicación por la Universidad Cardenal Herrera-CEU y licenciado en Ciencias de la Información por la Universidad Cardenal Herrera-CEU. Es miembro del Grupo de Investigación ITACA.-UJI de la Universitat Jaume I. Es técnico de Postproducción en la productora audiovisual Malvarrosa Media desde mayo de 2008. Más de 10 años de experiencia como técnico audiovisual en empresas como RTVV o Vocento. Ha recibido diversos premios. Ha sido árbitro de publicaciones en revistas indexadas, miembro de Tribunal en Tesis Doctorales y colabora desde 2010 con el “Master Universitario Internacional en Estudios de paz, conflictos y desarrollo. 